Review

\title{
Positive Welfare for Fishes: Rationale and Areas for Future Study
}

\author{
Isabel Fife-Cook and Becca Franks * \\ Department of Environmental Studies, New York University; New York City, NY 10003, USA; ifc219@nyu.edu \\ * Correspondence: krf205@nyu.edu
}

Received: 23 February 2019; Accepted: 7 May 2019; Published: 23 May 2019

\begin{abstract}
Traditional animal welfare paradigms have focused on maintaining physical health and mitigating negative impacts to wellbeing. Recently, however, the field has increasingly recognized the importance of positive welfare (i.e., mental and physical states that exceed what is necessary for immediate survival) and accordingly introduced manipulations and indicators of positive welfare for use in agriculture, laboratories, and zoos/aquaria. The creation and monitoring of positive welfare requires an in-depth knowledge of species-specific behavior and biology, which necessitates species-specific or, at a minimum, taxa-specific standards. Research on positive welfare in fish is lagging in this regard and therefore merits further consideration. In this paper, we aim to merge what is already known about positive welfare with the existing fish behavior literature to develop a plan of action for fish welfare research that will ultimately contribute to the development of positive welfare standards and assessment strategies for fish. We begin by exploring the origins of positive welfare research and then outline the physical, psychological and species-specific areas of inquiry that can be investigated in fish. In addition to presenting current findings on fish motivation, emotion, potential sources of positive welfare such as fulfillment of motivational urges (establishing agency, engaging in exploration and learning), and play behavior, we also identify promising areas for future research aimed at developing accurate and appropriate indicators of positive welfare in fish.
\end{abstract}

Keywords: animal behavior; fish welfare; positive welfare; welfare enhancement; negative and positive affect; motivation

\section{Introduction}

The past two decades have witnessed mounting interest in fish welfare and mounting interest in positive welfare, i.e., mental and physical states that exceed what is strictly necessary for short-term survival. To date, these trends have mostly progressed in parallel, with very little work at the intersection: positive welfare for fishes. Recent empirical (e.g., [1]) and theoretical breakthroughs [2-4], however, suggest that the time is ripe for such investigations; positive welfare can no longer be considered a luxury-it is critical to understanding and creating even minimally-acceptable welfare-and advances in fish behavior and cognition research $[5,6]$ point to many exciting areas for future work.

Historically, animal welfare science has focused on alleviating suffering (chronic stress, pain, etc.) and identifying physiological and behavioral signs of poor welfare, such as frequent illness, elevated blood cortisol and stereotypic behaviors [7]. Fish research has been no exception to this pattern. However, there is now a growing recognition among animal welfare scientists that pursuing the goal of relieving suffering does not lead to a lack of suffering $[4,8]$, thus indicating that even neutral animal welfare necessarily involves positive welfare.

Interestingly, in the early 2000s, human psychology came to a similar conclusion: that psychological science is not complete without understanding positive experiences and positive emotions [9]. This realization resulted in a new field of study (positive psychology) and the central insight that a life 
without positive experiences is not merely a neutral life, it is a bad life [9]. Positive experiences protect against boredom, languishing, and emotional distress, and positive emotions strengthen long-term well-being, resiliency, and even improve biological outcomes, such as increased cardiovascular health [10]. Similar patterns are now being identified across the animal kingdom $[4,11,12]$ and there is every indication that the same mechanisms function in fish as well.

The aim of this review is thus 2-fold. First, we wish to document the origins of positive welfare research, investigate its assessment parameters and highlight the significance of positive affect in animal husbandry. Second, we seek to explore the potential ways in which these concepts have been and could be applied to fish welfare research. In addressing these issues, we survey the current literature on positive welfare and identify three important areas of consideration for future work on positive fish welfare: (1) environmental inputs that are likely to produce positive welfare for fish, (2) assessing positive welfare in fish utilizing recent developments in emotion research, and (3) play behavior, which, under certain conditions, is consistent with aspects of positive welfare [13] and likely occurs in some species of fish [14].

\section{A Brief History of Positive Welfare Scholarship}

\subsection{Original Conceptualizations of Positive Animal Welfare}

Fraser and Duncan [7] were among the first welfare researchers to propose incorporating measures of positive affect into welfare assessment. They reasoned that if animals experience negative affective states (pain, hunger/thirst, fear, exhaustion, etc.), evolutionary theory suggests they should experience positive affective states as well. According to Fraser and Duncan [7], motivational affective states (MASs) evolved as separate processes to solve two different types of motivational problems; survival situations (what the animal needs) and opportunity situations (what the animal wants/likes). In both scenarios, the animal's affective state and resulting behavioral responses usually result in an evolutionarily advantageous outcome where the net outcome of the action on the animal's fitness is positive. Affective states are triggered by internal or external stimuli and subsequently motivate certain types of behavioral responses which can be positive (pleasure, joy, excitement, fulfillment, etc.) or negative (pain, hunger/thirst, fear, exhaustion, etc.). From an evolutionary standpoint, it is therefore in the animal's best interest to avoid prolonged negative affective states and promote positive states in order to optimize fitness.

Fraser and Duncan [7] suggested that analyzing behavior using their conceptual framework of positive and negative affect is necessary in order to generate a comprehensive assessment of an animal's welfare. Historically, welfare research has largely focused on mitigating prolonged need situations, i.e., those in which the animal is required to perform an action necessary to cope with threats to their survival and the resulting negative affective states, such as fleeing from a predator or searching for water during a drought. While providing relief from need situations will have a net beneficial effect on poor animal welfare, the most this approach can accomplish is to raise the welfare status from poor to neutral. While prolonged need situations are detrimental to animal welfare, their absence does not indicate positive affect. Fraser and Duncan [7] argued that providing animals with situations to promote positive affective states such as pleasure and joy are necessary to improve welfare past the neutral point. This work provided the imperative to incorporate positive welfare markers and use a combination of behavioral analysis and life history knowledge to predict when an aspect of animal management is likely to cause a positive reaction.

While the evolutionary theory and behavioral observations discussed by Fraser and Duncan [7] strongly suggested that positive emotions are not exclusive to humans, there was still little practical information regarding ways to promote positive affect in animals. Yeates and Main [15] were among the first ethologists to compile and publish a comprehensive review of positive welfare assessment methodology, suggesting that positive welfare should be evaluated on the basis of input (physical 
resources that are required or valued by an animal) as well as output (positive outcomes such as behavioral responses, cognitive processes and physiological markers indicative of positive affect) [15].

Experimental approaches that might allow researchers to explore animal happiness include physiological, behavioral and cognitive assessment. Yeates and Main [15] noted the utility of analyzing each source of evidence in context; for example, a behavior pattern appearing to be connected to a positive emotional experience can be corroborated by its display in appropriate contexts indicative of positive affect. Behavioral indicators of positive welfare involve activities typically performed when an animal's affective state is positive, such as, behavioral reactions to pleasant taste, vocalizations associated with outcomes expected to entail positive affect, and facial expressions associated with positive experiences [15]. Though the facial expressions of fishes are not well studied, many species of fish are known to be capable of producing distinct vocalizations that could be useful in discerning their general affect and it is reasonable to expect the possibility that fish display a range of physical and behavioral reactions in response to pleasant sensation (including changes in facial conformation).

Later, Balcombe [16] expanded on the evolutionary significance of positive affect, reiterating Fraser and Duncan's [7] claim that pleasure is adaptive as it motivates animals to partake in activities that benefit their fitness and evaluating potential sources of pleasure in animal life. In so doing, Balcombe [16] presented an overview of common behaviors likely to initiate or indicate positive affect, such as playing, engaging in sexual activity, eating and tactile stimulation.

\subsection{Current Thinking on Positive Animal Welfare}

The last decade has seen a marked increase in interest in positive animal welfare and proposed applications facilitating positive affect in animal husbandry guidelines. A number of prominent ethologists have advocated for incorporating positive welfare measures into existing welfare assessment paradigms. For example, Mellor [17] suggests incorporating positive welfare assessment into the Five Freedoms [18], arguing that fulfilling the Five Freedoms is not sufficient to ensure animal welfare as it ignores important psychological aspects of welfare beyond the animal's immediate physical and biological needs. Similarly, Mellor and Beausoleil [19] propose modifying the Five Domains model of animal welfare developed by Mellor and Reid to include a measure of positive welfare in each domain (see [17] for a table of Five Freedoms and updates for positive welfare).

Other scientists have proposed incorporating methods used in human psychology into existing animal welfare assessment paradigms. Mellor [20] presents a neuropsychological explanation of the relationship between emotions and behavior in animals based on a model of action-oriented systems previously described in humans. Webb et al. [21] suggest adopting human quality of life indicators into animal welfare assessment methodology as a framework for quantifying and assessing animal happiness.

Most recently, ethologists have proposed methods of incorporating positive animal welfare indicators into animal husbandry and management guidelines. Lawrence, Newberry and Spinka [22] propose applying positive welfare assessments in order to improve the quality of animal life in pig-keeping, highlighting the overwhelming bias towards negative welfare research thus far. Similarly, Whitham and Wielebnowski [23] and Wolfensohn [24] suggest incorporating positive welfare into standard animal welfare assessment guidelines used by zoos and aquariums (such as the Animal Welfare Assessment Grid).

\section{Motivation and Environmental Inputs}

What types of environments and opportunities are likely to create positive welfare for fishes? In general, animal welfare relies on understanding what the animals want, which provides a starting place for testing ideas regarding what inputs are likely to be needed for ensuring welfare [25]. For example, a seminal study in mink (Neovison vison) used behavioral economic principles and methodology to show that mink will push heavily weighted doors to access swimming pools but will 
not push as hard for access to slightly more (empty) space. Importantly, this program of research also showed that consistent with their motivational preferences, mink experience increased stress when they are prevented from having access to swimming opportunities, but not when they are prevented from having access to slightly more space [26]. Recent studies have used similar experimental designs in fish to show, for example, that goldfish will swim against a current to access plants [27] and that a species of cichlid, Mozambique tilapia (Oreochromis mossambicus), will push against a door to access social partners [28]. Before the experiment is designed and the data collected, however, the model of motivation inspiring the study plays an outsized and sometimes hidden role in the type of information that is gained from the research [29].

Thus far, the predominant model of motivation in animal welfare has been an implicit model that is focused on modifying physical parameters within the current systems of use, e.g., agriculture, laboratories, zoos and aquaria. While this informal 'model' has provided invaluable information regarding the elements that need to be changed to mitigate and alleviate potential suffering, it has been less useful for answering questions related to positive welfare. The creation of positive welfare requires a more sophisticated model of motivation, one that is not merely reactionary to currently suboptimal conditions, but instead identifies promising areas of investigation for the goal of creating a full and fulfilling life.

Recent work in human psychology provides one such model of motivation. Higgins [30] has identified three domains to consider in motivation research: (1) value effectiveness, the motivation to have valued outcomes (and avoid aversive ones), (2) control effectiveness, the motivation to be in control or be agentic, and (3) truth effectiveness, the motivation to learn and have opportunities for cognitive engagement. Evidence for these three domains can be found throughout the animal kingdom [12], indicating that this model may also serve as a useful framework for developing hypotheses related to what inputs may promote positive welfare in fish.

\subsection{Motivation for Value Effectiveness}

To date, the most studied domain of motivation in animal welfare is value effectiveness: the motivation to have or to avoid specific material outcomes. Classic animal welfare research that falls into this category has shown, for instance, that hens are highly motivated to access nest boxes before laying [31]. Work related to value effectiveness has been conducted in many species of fish as well. One recent study used a preference index to assess Nile tilapias' (Oreochromis niloticus) motivation over time for different tank wall colors [32] and other work has shown that male tilapia's (O. mossambicus) substrate preference is conditional on social context [33]. Similarly, other work has shown that Coho salmon (Oncorhynchus kisutch) have a strong preference to be in environments with dark backgrounds and, when restricted to lighter backgrounds, are four times more aggressive than when they have access to dark backgrounds [34].

While value effectiveness is often used to identify husbandry features that might cause suffering by their presence (e.g., aversive ambient conditions) or absence (e.g., preferred substrate), it can also stimulate hypotheses for resources that might promote positive affective states. For example, research designed to identify which food sources a fish is most motivated to eat (regardless of nutritional content), could provide ideas for food items to periodically introduce into their diet to create sensory pleasure [16]. Similarly, studies assessing the motivation to access hiding structures would be a first step to understanding what design features may best promote a sense of safety and security in fish.

\subsection{Motivation for Control Effectiveness}

Control effectiveness refers to the desire to manage or control what happens [30]. In other words, beyond the desire to simply have good outcomes (which would be classified as value effectiveness), studies in many different species have indicated that animals are also motivated to be agentic, to be the one who brings the desired outcome about [12,35]. Support for the importance of a distinct motivation for control effectiveness can be found across the animal behavior and welfare literature, 
including recent work on animal agency $[2,11]$, the proposed relationship between predictability and animal welfare [36], and contrafreeloading studies, some of which date back to the middle of the last century [37]. The common thread throughout all these lines of research is the evidence that animals are interested in taking action, often rejecting opportunities to be passive recipients of desired end-states and benefiting from opportunities have more control over their lives.

While we are not aware of any research directly assessing motivation for control effectiveness in fish, there are several studies that indicate it is a promising domain to consider. For example, Nile tilapia were found to have improved immune function and lower stress levels when they had control over their feeding schedule [38]. This study employed a yoked design in which half the fish were given access to a device that allowed them to trigger the release of food on demand. The other half of the fish received food on a 'yoked' schedule, matched to when the first group activated the food device. This design thus kept the material outcomes and their timing constant across both conditions; the only difference was that one group had control (agency) whereas the other did not. As such, the improved immune function (which, in addition to positive welfare, may have added production value), can be traced to the increased agency in the self-feeding group.

More work in the domain of control effectiveness in fish is clearly needed and the large body of evidence across species of terrestrial animals [11,12] points towards several promising areas for future fish welfare research. In particular, contrafreeloading studies-which assess the degree to which animals will perform unnecessary work (e.g., lever pressing or foraging behaviors) for freely available resources-could investigate whether fish contrafreeload and if they do, determine what sorts of work they enjoy most.

Another methodology that may be useful for examining whether fish are motivated to have control is conditioned place preference (CPP) paradigms, which involve training an individual to associate a neutral environment with a certain type of experience (e.g., receiving a reward). If the animal perceives the experience to be positive, the originally neutral environment will eventually become preferred and if the animal perceives the experience to be negative, the originally neutral environment will eventually become aversive. As CPPs have already been successfully demonstrated in some species of fish including zebrafish (Danio rerio) [39] and gilthead sea bream (Sparus aurata) [40], CPP studies represent a promising avenue for future research of this kind. If fish are motivated to have control or be agentic, we would expect future research to show that fish develop CPPs for environments in which they experience control opportunities.

\subsection{Motivation for Truth Effectiveness}

The third domain to consider is truth effectiveness, the motivation to learn, explore, and engage in cognitively stimulating activities [30]. The motivation for truth effectiveness is distinct from the motivations for value effectiveness and control effectiveness in that it refers to the motivation for gathering and processing information. In other words, beyond the desire to simply have good outcomes (value effectiveness) and to make good outcomes happen (control effectiveness), studies in many different species have indicated that animals are also motivated to explore, solve problems, and understand patterns [12,35].

Evidence for truth effectiveness motivation in nonhuman animals dates back to classic studies from the middle of the 20th century, with Harlow's [41] work on problem-solving behavior in monkeys and Berlyne's [42] investigations into curiosity in rats. Since then, many other species have been found to want to engage in information processing activities, causing scientists to refer to a fundamental exploratory motive [43] and link problem-solving opportunities to animal welfare [44]. Most recently, there is mounting interest in animal boredom, which is a potentially underappreciated welfare risk and, without appropriate cognitive stimulation, one which many captive animals are likely to suffer $[3,4,45]$.

Existing evidence suggests that at least some species of fish have a motivation for truth effectiveness. Anecdotally, fish are often noted for their curiosity, i.e., the motivation for information-for example, the observation that in experimental settings, some species of fish are known to explore a maze even 
after it has been solved. There is also some scientific work to support this impression [14]. For example, experimental work has shown that European minnows (Phoxinus phoxinus) have a strong propensity to inspect novel objects [46] and when given the opportunity, zebrafish will readily inspect new spaces [47].

Novelty and exploration are not inevitably motivating to animals, however. Most species find forced exposure to novel environments and unfamiliar objects to be aversive, which is why these manipulations are often used to assess negative emotions such as anxiety, stress, and fear. Indeed, one of the most commonly used tests of negative affective state in fish is the novel tank diving paradigm [48]. The key difference between these types of tests and those that can reveal an animal's desire for exploration is whether exposure to the novelty is voluntary or forced. Under forced-choice exploration paradigms, animals often show signs of aversion, whereas under free-choice paradigms, animals often show signs of preference for information gain [43]. Thus, future work aimed at assessing the degree to which fish species may be motivated for learning, exploration, and problem solving (i.e., truth effectiveness), should employ free-choice paradigms whenever possible and ensure that fish have access to a familiar, safe shelter in which they can retreat if a novel experience becomes overwhelming.

Providing fish with environmental enrichment [49] designed to increase complexity while mimicking their natural habitat may be an effective way to offer choice, encourage exploration, and facilitate curiosity. While determining appropriate enrichment strategies is highly dependent on the species' natural history, there are some principles that have been found to be successful in generating positive effects on a variety of species used in research and aquaculture. In general, many species of captive fish benefit from the incorporation of species-appropriate substrate, tank color, structural complexity and sensory stimulation provided by aquatic plants and submerged structures such as logs or rocks. For a comprehensive overview of current environmental enrichment research for captive fishes, see Näslund and Johnsson [49].

\section{Positive Emotion}

The study of emotions in animals has received a growing interest in the past few decades, as evidenced by the emergence of a new discipline referred to as Affective Neuroscience [50] and fish research has been no exception to this trend $[1,51]$. From an evolutionary perspective, emotions are considered to be adaptive programs intended to direct other physiological responses or directly solve adaptive problems faced by a species over time, defined as intense but short-lived affective responses to an event manifested through physical changes [50]. Emotion is classically described as including a behavioral component, an autonomic component (physiological and endocrine responses) and a subjective component (emotional experience or feeling), and can thus be assessed using both physiological and behavioral parameters [50].

\subsection{Physiological Indicators of Positive Emotion}

Changes in physiological parameters such as heart rate, blood pressure and levels of adrenaline and/or cortisol are often used as indicators of emotions. However, physiological markers should ideally be paired with a behavioral assessment as physiology on its own may indicate sensory arousal but not necessarily emotional valence [51].

The link between rewarding behavior and positive emotion has been established through both behavioral and neuropsychological analysis. Appetitive (seeking/wanting) behaviors or incentive salience have been associated with the release of dopamine from the mesolimbic pathway, a neural pathway found in most vertebrates (including fish) that is responsible for facilitating reinforcement and reward-related motor function learning and plays a role in the subjective perception of pleasure [52], while consummatory (liking) behaviors have been associated with opioids [50]. Social behavior, reproductive behavior, play, self-grooming and other maintenance behaviors all have rewarding properties, releasing endorphins which activate the mesolimbic system, establishing a positive feedback loop and corresponding behavioral expression. Conversely, deprivation of opportunities 
to perform specific rewarding behaviors produces signs of withdrawal paralleling those observed in deprivation of an addictive drug, further reinforcing the link between rewarding behavior and pleasurable experience [50].

Emotional limbic activity has been shown effect immune function in vertebrates, suggesting that immune activity may prove a promising tool in investigating emotion [50]. In pigs, positive and negative emotional experiences affected immune system parameters (s-IgA levels) antagonistically, paralleling results of experiments on the relationship between emotion and immune function in humans [50]. It should be noted that immune system function is influenced by a plethora of external and internal factors and should therefore only be used to assess emotional valence in in conjunction with other physiological or behavioral markers.

Physiological evidence suggests that fish possess the necessary anatomical and chemical structures to experience emotion [6,51]. It appears that emotions involve brain circuits that have been conserved and elaborated upon throughout vertebrate evolution [53]. The fish telencephalon has homologous limbic and dopaminergic structures involved in emotional processing similar to the mammalian amygdala and hippocampus. Additionally, fish show stress responses similar to mammals, releasing adrenaline and noradrenaline during fear and stress responses, resulting in increased heart rate and ventilation. Fish also produce cortisol in response to emotional stimuli and express transmitter substances including dopamine, serotonin and oxytocin/isotocin associated with reward and mood in humans $[54,55]$. Finally, multiple studies have shown that fish possess the physiological criteria for pain perception including nociceptors, natural pain-killers (opioids), neural pathways and other brain areas involved in pain perception [56-58].

\subsection{Behavioral Indicators of Positive Emotion}

A number of behaviors, many of which have been documented in fish [14], can signal positive emotional experience in animals, including successful coping, accessing reward, and successful goal-directed behavior. Boissy et al. [50] propose monitoring five behavioral expressions of positive welfare; play behavior, affiliative behavior, self-grooming, vocalizations, and information-gathering. Most research on positive emotion in fish has focused on affiliative and play behaviors, the latter of which is discussed in the section on play.

A potential source of positive emotion in gregarious species is communication and social bonding [59]. As social bonding is a critical element of survival in many species, it follows that pro-social behaviors incorporating fitness benefits may indicate positive emotional states. Pro-social affiliation is likely a good starting place to explore positive emotions in fish as they have various communication modalities [51] and diverse and complex social behaviors.

For example, many fish species have the ability to recognize each other as individuals and some also exhibit parental care [51]. Similarly, some species of cichlids form monogamous pairs and have helpers, constructing a social group of fish of both sexes who share in defending territory and the brood [51]. Studies on zebrafish (Danio rerio) have shown that proximity to a conspecific has rewarding properties and that even mere visual contact with a conspecific can be used to reinforce behavior in an associative learning task [60]. Allogrooming represents another group activity that has been linked to positive emotion, such as inducing a relaxed state [50] in fish and other vertebrates. In fish, it has been shown that tactile stimulation can lower stress levels [61] and facilitate future pro-social interactions [62]. Taken as a whole, these lines of research indicate that, under certain circumstances, the presence of a conspecific and pro-social behavior is likely to involve positive emotional responses in some species of fish.

Following this line of reasoning, Franks et al. [63] evaluated a distinct type of shoaling behavior, heightened shoaling, in order to determine its candidacy as a behavioral indicator of positive emotion in zebrafish. Continuous scans of six 30-L tanks of zebrafish housed in semi-natural conditions (sloping gravel substrate, artificial plants, and rocks) revealed multiple instances of this unique and discrete behavior: distinct episodes of abnormally high group cohesion and synchrony, typically lasting for 
approximately $7 \mathrm{~min}$, but sometimes as long as $30 \mathrm{~min}$. Because these episodes of heightened shoaling were also characterized by low aggression and seemed to occur spontaneously, due to internal group dynamics alone, they share many of the features that are associated with positive emotion in other species [50]. This study underlines the need for a better understanding of species-specific behavior under naturalistic condition in order to successfully evaluate the true behavioral repertoire that may be indicative of positive emotion $[7,50]$.

Communication is another promising area of study, although it should be noted that traditional methods of evaluating social communication in animals may not be applicable to fishes. Rather than relying on anthropocentric behavioral manifestations of pleasure such as facial expressions, we suggest investigating alternate behavioral indicators of positive affect specific to fish, including vocalizations [64], chemical signaling [51], coloration changes, electrical impulses, and bioluminescence. In sum, there is a diversity of potential for future work in identifying behaviors indicative of positive emotions in fish.

\subsection{Eliciting Positive Emotion in Fish}

Boissy et al. [50] propose several practical ways of promoting positive experiences in farmed animals, in both the short and long term: positive anticipation (signaling or predicting a reward in advance), positive contrast (giving a higher reward than expected) and coping and controllability (enabling the animals to cope with or to control the situation). These interventions can all be applied to and tested in fish, suggesting many fruitful ideas for how positive emotions might be elicited and studied in fish.

Anticipation of a positive or rewarding event induces a state of positive affect. Investigations of what animals find positively reinforcing and of the animal's behavioral expression during anticipation or expectation of the rewarding result provide a basis for assessing positive emotional states in animals [50]. Such work (some of it dating back decades) has already been conducted in several species of fish. A recent example comes from work by Nilsson [65], who used conditioning and trained groups of cod (Gadus morhua) to associate a light signal with a positive up-coming event, i.e., the delivery of food. The fish showed anticipatory behavior and gathered in the feeding area after they had been presented with the light signal.

Positive contrast, on the other hand, describes the experience of receiving an outcome that is better than expected. In a typical positive contrast experiment, an animal is first trained to expect a reinforcer of a certain size. The test phase occurs when the expected reward is replaced by an even stronger or larger reinforcer (e.g., more food or better-quality food). If the animal changes its behavior so that its response is faster/more vigorous than that of a control group given the larger reinforcer from the start, a successive positive contrast (SPC) has occurred [50]. Interestingly, an early study by Bottjer, Scobie and Wallace [66] found behavior in goldfish (Carassius auratus) that is consistent with a positive contrast effect. In this study, goldfish in the positive contrast condition responded at a higher rate to the conditioned stimulus (a light cue) than fish in the control condition, despite the fact that the reinforcement level (i.e., food amount) was the same for both groups. Given the cognitive sophistication found in many species of fish [5], it is likely that other species of fish may experience positive contrast (i.e., are able to track the relative value of a reward rather than it's absolute value), which suggests that positive contrast may be a promising area for future research on positive emotion in fish.

Finally, scholars have suggested that successful coping and exerting control over the environment can also increase positive welfare [12]. While facing challenges inevitably involves some degree of stress, only chronic stress brought about by the persistent inability to cope causes long-term distress and learned helplessness [50]. In contrast, short-term social and physical challenges can be perceived as positive engagement experiences when the net result is a learned coping behavior and/or rewarding goal. In other words, if there is a high probability of success, challenges can actually be a source of positive welfare. Studies applying learning procedures with positive reinforcement, for example, are likely to reflect the behavior of fish experiencing positive emotion in response to a cognitive challenge. 


\section{Play}

Play has fascinated scholars for millennia and yet it remains a highly contentious area of study for many reasons, not the least of which is that play behavior can be hard to define and identify $[7,13]$. Nonetheless, part of the root of the scientific fascination with play stems in part from the notion that under certain conditions, play may be associated with positive emotions and signal improved welfare. Indeed, some scholars have identified it as one of the most promising indicators of positive emotions in domestic animals in part because it can be measured noninvasively and can be easily recognized in some mammals $[7,13,50]$. Identifying and measuring play behavior in non-mammalian species is, however, much more challenging due to its variability between species and mutable characteristics [67]. Moreover, the relationship between play and welfare and especially positive emotions is complex and controversial $[13,68]$. Thus connections between play and positive welfare require more work before the implications of observing different types of play at different levels in different species held under different conditions are known. With due consideration of these qualifications, however, play remains an intriguing avenue for future research on positive welfare in fish for reasons we outline below.

\subsection{Identifying and Assessing Play in Fishes}

First, a large body of anecdotal evidence and some empirical work suggests that play exists in many species of fish [14,67]. How might we assess play behavior in fish? Ethologist Gordon Burghardt [14] presents a working method for identifying play behavior based on five criteria. While aspects of these criteria can be somewhat subjective, they represent a useful starting point for flagging behaviors that may be good candidates for future research. Burghardt's core criteria are as follows:

1. Play behaviors are typically not fully functional and are often directed toward stimuli that do not contribute to immediate survival.

2. Play is autotelic (self-rewarding) and is often characterized as something that animals seem to engage in voluntarily. Play behaviors appear to be spontaneous, intrinsically motivated, rewarding, reinforcing or pleasurable.

3. Play behaviors may resemble 'serious' performance of ethotypic behavior but differ in structure and/or timing to adult behavior. Play behavior is "incomplete, exaggerated, awkward, or precocious" and "involves behavior patterns with modified form, sequencing, or targeting" [14].

4. Play is performed repeatedly, but not stereotypically during at least one developmental period in life" [14].

5. Play is initiated when the animal is in a relaxed state, i.e., when there are no immediate threats to the animal's fitness and the animal is not strongly motivated to perform other behaviors.

Burghardt [14] argues that fish possess the necessary behavioral and cognitive pre-requisites that support play behavior in other animals, including exploration and curiosity. The existing evidence for play in fish are discussed below along with the main types of play.

Social play involves two or more animals usually of similar age and size [13,69] and facilitates integration into groups and social skills [70,71]. As such, social play is more commonly observed in young animals than adults, though it is known to occur at lower frequencies in adults of some species [14]. Burghardt [14] reports anecdotal accounts suggestive of social play in several cichlid species. For example, Burghardt [14] describes an instance in which a socially-housed white spotted cichlid (Tropheus duboisi) was observed repeatedly approaching a cichlid species from Lake Malawi (Labeotropheus sp.), performing a lateral display and eliciting a brief chase, a potential example of teasing play [14]. Similarly, young cichlid (sp) are often observed nibbling and rubbing against their parent's flanks, which may be play behavior as it does not appear to serve any adaptive function [14]. Controlled and systematic observation of these types of fish social behavior, especially between neonatal cichlids and their parents, would be useful for determining whether they are consistent with our understanding of play. 
Object play is directed at inanimate objects and can involve one or more participants [14]. It is typically observed when animals manipulate objects that appear to provide no obvious survival benefit [14] and is thought to be related to the development of motor skills [69]. Observations of object play have been observed across a wide range of fish species. For example, many species of captive fish have been reported repeatedly manipulating objects within their environment for no immediately obvious function [14] and anecdotal evidence suggests some predatory species such as great white sharks (Carcharodon carcharias) may hunt for fun when prey is not needed for nourishment. Most recently, an empirical study systematically observed the object manipulation behavior of white spotted cichlids (Tropheus dubois) and found that their behavior was consistent with all the criteria for play behavior [67]. The provision of sensory-stimulating objects may be a good starting place for further empirical work on object play in fish.

Locomotor play involves jumping, running and performing other motor activities in a sudden, persistent and frenetic manner $[14,69,71]$. It is thought that locomotor play serves to benefit the animal physiologically by promoting muscle growth, strengthening bones and increasing cardiopulmonary capability [13]. Perhaps the most well-documented example of locomotor play in fish is leapfrogging, in which individuals repeatedly launch themselves over objects floating in the water such as plants, leaves, sticks and other animals. Burghardt [14] notes that leapfrogging has been reported in needlefish, Hemiramphidae (halfbeaks), Clupeidae (herring and shad) and Atherinidae (silversides) and outlines several hypotheses attempting to explain the origins and purposes of leapfrogging, including the idea that leapfrogging may be an instinctive means of ectoparasite control or to elicit a pleasurable tactile sensation. Most recently, Fagen [72] has argued that jumping behavior is likely a form of locomotor behavior in Atlantic salmon (Salmo salar).

\subsection{The Play-Welfare Relationship}

Play is often used to assess affective states in both human and nonhuman animals $[14,68]$ and is gaining interest in applied ethology as a welfare indicator [50,69]. The first clue that play behavior is important to animal welfare is its absence in poor welfare situations. Play behavior often disappears when animals are under fitness challenges but re-emerge as they recover [13]. As such, the absence of play, particularly in young animals, is considered an indication of poor welfare.

Importantly, however, play behaviors also change in timing or kind in conjunction with a decrease in welfare. Research in children suggests that, beyond the total duration of play, poor welfare may be reflected in qualitative aspects such as the display of solitary over social play and the degree to which play bouts are continuous vs. fragmented. Play research aimed at understanding the play-welfare relationship should, therefore, attend to the quality (type and fragmentation) and timing in addition to its quantity [68]. Future work on fish play could begin by mapping out the range of potential play behaviors and its qualitative characteristics across different conditions, which is a necessary starting point before strong inferences to welfare are drawn.

Overall, however, play is most common in situations when the animal is well fed and not under any threat to fitness [68]. This positive association between play behavior and need fulfillment provides the basic foundation for the link between play behavior and animal welfare [13,50]. Fraser and Duncan [7] argue that certain behaviors are indicative of internal states; according to their theory of animal welfare, play occurs when an animal is in an opportunity situation in which their immediate physical needs are met and the behavior results in a net positive impact to their fitness (i.e., the pleasure derived from performing the activity eclipses the fitness cost of performing that activity).

Play can be used both a behavioral indicator of good welfare but also as tool to promote it [13]. Several studies have documented the contagious nature of play amongst conspecifics, suggesting that one playful individual can trigger a cascade of positive affect, resulting in substantial welfare benefits to social animals. Social learning, which involves an element of contagious behavior, has been documented extensively in teleost species [73,74], suggesting that future research on fish social interaction may yield important results to welfare. For example, Held and Spinka [13] suggested stimulating social 
play behavior in captive animals by providing the opportunity for positive social communication, a scenario that could be applied to captive fish by housing individuals in social groups of appropriate size and composition.

Future research with fish could leverage these intriguing ideas and follow up on the anecdotal observations outlined by Burghardt [14]. Importantly, however, such research requires housing fish in environmental and social conditions conducive to a relaxed state. Furthermore, the current relative paucity of documented play behavior in fish may not indicate that fish do not play but rather that they are too uncomfortable in the typical housing we provide for them to engage in play. The first steps towards studying play behavior and by extension the relationship between play and welfare in fish is therefore to provide animals with social and environmental conditions conducive to a relaxed state in which their needs are met.

\section{Conclusions}

Drawing from existing literature on welfare paradigms in both human and nonhuman animals, we identified potential physiological and behavioral signifiers likely involved with positive welfare in fish and suggest future research that could support the ways in which caretakers can promote positive welfare in captive fish including the provision of species-appropriate housing (e.g., ambient color) and social conditions as well as opportunities for control (e.g., self-feeders) and cognitive engagement (e.g., visual stimulation via port holes and/or novel objects). Incorporating indicators of positive affect into fish welfare assessment strategies will be particularly important given the growing number of captive fish for whose wellbeing humans are primarily responsible. In particular, generating scientific knowledge on ways of identifying and monitoring species-specific indications of positive affect is an essential step forward in understanding fish welfare.

In closing, it is worth clarifying that we are not advocating for positive welfare as a distinct field of research. Separating positive welfare from negative welfare is likely an artificiality, creating the impression of welfare as a static contrast between immediate pleasure and immediate suffering. In psychology, it has been argued that there is no positive psychology or negative psychology, there is only psychology [75]; similarly, rather than categorizing welfare into positive vs. negative types, it may be more useful to have the simple goal of understanding welfare and making sure that that understanding is complete. Thus, the aim of this review was not to present a new and separate area of study but rather to highlight a class of experiences and emotions that are currently being neglected and issue the call for more research in these areas.

Author Contributions: Individual contributions include: Conceptualization, B.F. \& I.F.-C.; investigation, B.F. \& I.F.-C.; writing-original draft preparation, B.F. \& I.F.-C.; writing-review and editing, B.F. \& I.F.-C.; supervision, B.F.; funding acquisition, B.F. \& I.F.-C.

Funding: This research was funded in part by a generous donation to the Fish and Marine Animal Welfare Fund at New York University. IFC received support from the Animal Law and Policy (ALP) Program at UCLA.

Conflicts of Interest: The authors declare no conflict of interest. The funders had no role in the design of the study; in the collection, analyses, or interpretation of data; in the writing of the manuscript, or in the decision to publish the results.

\section{References}

1. Cerqueira, M.; Millot, S.; Castanheira, M.F.; Félix, A.S.; Silva, T.; Oliveira, G.A.; Oliveira, C.C.; Martins, C.I.M.; Oliveira, R.F. Cognitive Appraisal of Environmental Stimuli Induces Emotion-like States in Fish. Sci. Rep. 2017, 7, 13181. [CrossRef]

2. Špinka, M. Animal Agency, Animal Awareness and Animal Welfare. Anim. Welf. 2019, 28, 11-20. [CrossRef]

3. Meagher, R. Is Boredom an Animal Welfare Concern? Anim. Welf. 2019, 28, 21-32. [CrossRef]

4. Burn, C.C. Bestial Boredom: A Biological Perspective on Animal Boredom and Suggestions for Its Scientific Investigation. Anim. Behav. 2017, 130, 141-151. [CrossRef]

5. Brown, C. Fish Intelligence, Sentience and Ethics. Anim. Cogn. 2015, 18, 1-17. [CrossRef] [PubMed] 
6. Braithwaite, V.A.; Huntingford, F.; van den Bos, R. Variation in Emotion and Cognition Among Fishes. J. Agric. Environ. Ethics 2013, 26, 7-23. [CrossRef]

7. Fraser, D.; Duncan, I.J.H. "Pleasures", "pains" and Animal Welfare: Toward a Natural History of Affect. Anim. Welf 1998, 7, 383-396.

8. Mellor, D.J. Moving beyond the "Five Freedoms" by Updating the "Five Provisions" and Introducing Aligned "Animal Welfare Aims". Animals 2016, 6, 59. [CrossRef]

9. Seligman, M.E.P.; Csikszentmihalyi, M. Positive Psychology-An Introduction. Am. Psychol. 2000, 55, 5-14. [CrossRef]

10. Fredrickson, B.L. Positive Emotions Broaden and Build. In Advances in Experimental Social Psychology; Devine, P.G., Plant, A., Eds.; Academic Press: Burlington, MA, USA, 2013; pp. 1-53.

11. Špinka, M.; Wemelsfelder, F. Environmental Challenge and Animal Agency. In Animal Welfare; Appleby, M.C., Ed.; CAB International: Wallingford, UK, 2018; pp. 39-55.

12. Franks, B.; Higgins, E.T. Effectiveness in Humans and Other Animals: A Common Basis for Well-Being and Welfare. Adv. Exp. Soc. Psychol. 2012, 46, 285-346. [CrossRef]

13. Held, S.D.E.; Špinka, M. Animal Play and Animal Welfare. Anim. Behav. 2011, 81, 891-899. [CrossRef]

14. Burghardt, G.M. The Origins of Vertebrate Play: Fish That Leap, Juggle, and Tease. In The Genesis of Animal Play: Testing the Limits; MIT Press: Cambridge, MA, USA, 2005.

15. Yeates, J.W.; Main, D.C.J. Assessment of Positive Welfare: A Review. Vet. J. 2008, 175, 293-300. [CrossRef]

16. Balcombe, J. Animal Pleasure and Its Moral Significance. Appl. Anim. Behav. Sci. 2009, 118, $208-216$. [CrossRef]

17. Mellor, D.J. Updating Animal Welfare Thinking: Moving beyond the "Five Freedoms"; towards "A Life Worth Living". Animals 2016, 6, 21. [CrossRef]

18. Brambell, F. Report of the Technical Committee to Enquire into the Welfare of Animals Kept under Intensive Livestock Husbandry Systems; Her Majesty's Stationery Office: London, UK, 1965.

19. Mellor, D.; Beausoleil, N. Extending the "Five Domains" Model for Animal Welfare Assessment to Incorporate Positive Welfare States. Anim. Welf. 2015, 24, 241-253. [CrossRef]

20. Mellor, D. Animal Emotions, Behaviour and the Promotion of Positive Welfare States. N. Z. Vet. J. 2012, 60, 1-8. [CrossRef]

21. Webb, L.E.; Veenhoven, R.; Harfeld, J.L.; Jensen, M.B. What Is Animal Happiness? Ann. N. Y. Acad. Sci. 2019, 1438, 62-76. [CrossRef]

22. Lawrence, A.B.; Newberry, R.C.; Špinka, M. Positive Welfare: What Does It Add to the Debate over Pig Welfare? In Advances in Pig Welfare; Elsevier, Inc.: Amsterdam, The Netherlands, 2018. [CrossRef]

23. Whitham, J.C.; Wielebnowski, N. New Directions for Zoo Animal Welfare Science. Appl. Anim. Behav. Sci. 2013, 147, 247-260. [CrossRef]

24. Wolfensohn, S.; Shotton, J.; Bowley, H.; Davies, S.; Thompson, S.; Justice, W.; Wolfensohn, S.; Shotton, J.; Bowley, H.; Davies, S.; et al. Assessment of Welfare in Zoo Animals: Towards Optimum Quality of Life. Animals 2018, 8, 110. [CrossRef]

25. Dawkins, M.S. From an Animal's Point of View: Motivation, Fitness, and Animal Welfare. Behav. Brain Sci. 1990, 13, 1-9. [CrossRef]

26. Mason, G.J.; Cooper, J.; Clarebrough, C. Frustrations of Fur-Farmed Mink. Nature 2001, 410, 35-36. [CrossRef] [PubMed]

27. Sullivan, M.; Lawrence, C.; Blache, D. Why Did the Fish Cross the Tank? Objectively Measuring the Value of Enrichment for Captive Fish. Appl. Anim. Behav. Sci. 2016, 174, 181-188. [CrossRef]

28. Galhardo, L.; Almeida, O.; Oliveira, R.F. Measuring Motivation in a Cichlid Fish: An Adaptation of the Push-Door Paradigm. Appl. Anim. Behav. Sci. 2011, 130, 60-70. [CrossRef]

29. Franks, B. What Do Animals Want? Anim. Welf. 2019, 28, 1-10. [CrossRef]

30. Higgins, E.T. Beyond Pleasure and Pain: How Motivation Works; Oxford University Press: New York, NY, USA, 2012.

31. Cooper, J.J.; Appleby, M.C. Motivational Aspects of Individual Variation in Response to Nestboxes by Laying Hens. Anim. Behav. 1997, 54, 1245-1253. [CrossRef] [PubMed]

32. Maia, C.M.; Volpato, G.L. Preference Index Supported by Motivation Tests in Nile Tilapia. PLoS ONE 2017, 12 , e0175821. [CrossRef] [PubMed]

33. Galhardo, L.; Almeida, O.; Oliveira, R.F. Preference for the Presence of Substrate in Male Cichlid Fish: Effects of Social Dominance and Context. Appl. Anim. Behav. Sci. 2009, 120, 224-230. [CrossRef] 
34. Gaffney, L.P.; Franks, B.; Weary, D.M.; von Keyserlingk, M.A.G. Coho Salmon (Oncorhynchus kisutch) Prefer and Are Less Aggressive in Darker Environments. PLoS ONE 2016, 11, e0151325. [CrossRef]

35. Higgins, E.T.; Cornwell, J.F.M.; Franks, B. "Happiness" and "The Good Life" as Motives Working Together Effectively. In Advances in Motivation Science; Academic Press: Cambridge, MA, USA, 2014; Volume 1, pp. 135-179.

36. Bassett, L.; Buchanan-Smith, H.M. Effects of Predictability on the Welfare of Captive Animals. Appl. Anim. Behav. Sci. 2007, 102, 223-245. [CrossRef]

37. Osborne, S.R. Free food (contrafreeloading) phenomenon-Review and analysis. Anim. Learn. Behav. 1977, 5, $221-235$. [CrossRef]

38. Endo, M.; Kumahara, C.; Yoshida, T.; Tabata, M. Reduced Stress and Increased Immune Responses in Nile Tilapia Kept under Self-Feeding Conditions. Fish. Sci. 2002, 68, 253-257. [CrossRef]

39. Wong, D.; von Keyserlingk, M.A.; Richards, J.G.; Weary, D.M. Conditioned Place Avoidance of Zebrafish (Danio Rerio) to Three Chemicals Used for Euthanasia and Anaesthesia. PLoS ONE 2014, 9, e88030. [CrossRef] [PubMed]

40. Millot, S.; Cerqueira, M.; Castanheira, M.F.; Øverli, Ø.; Martins, C.I.M.; Oliveira, R.F. Use of Conditioned Place Preference/Avoidance Tests to Assess Affective States in Fish. Appl. Anim. Behav. Sci. 2014, 154, 104-111. [CrossRef]

41. Harlow, H.F. Learing and satiation of response in intrinsically motivated comples puzzle performance by monkeys. J. Comp. Physiol. Psychol. 1950, 43, 289-294. [CrossRef] [PubMed]

42. Berlyne, D.E. Curiosity and Exploration. Science 1966, 153, 25-33. [CrossRef] [PubMed]

43. Hughes, R. Intrinsic Exploration in Animals: Motives and Measurement. Behav. Processes 1997, 41, $213-226$. [CrossRef]

44. Meehan, C.L.; Mench, J.A. The Challenge of Challenge: Can Problem Solving Opportunities Enhance Animal Welfare? Appl. Anim. Behav. Sci. 2007, 102, 246-261. [CrossRef]

45. Franks, B. Cognition as a Cause, Consequence, and Component of Welfare. In Advances in Agricultural Animal Welfare; Woodhead Publishing: Duxford, UK, 2018.

46. Murphy, K.E.; Pitcher, T.J. Individual Behavioural Strategies Associated with Predator Inspection in Minnow Shoals. Ethology 1991, 88, 307-319. [CrossRef]

47. Graham, C.; von Keyserlingk, M.A.G.; Franks, B. Free-Choice Exploration Increases Affiliative Behaviour in Zebrafish. Appl. Anim. Behav. Sci. 2018, 203, 103-110. [CrossRef]

48. Egan, R.J.; Bergner, C.L.; Hart, P.C.; Cachat, J.M.; Canavello, P.R.; Elegante, M.F.; Elkhayat, S.I.; Bartels, B.K.; Tien, A.K.; Tien, D.H.; et al. Understanding Behavioral and Physiological Phenotypes of Stress and Anxiety in Zebrafish. Behav. Brain Res. 2009, 205, 38-44. [CrossRef]

49. Näslund, J.; Johnsson, J.I. Environmental Enrichment for Fish in Captive Environments: Effects of Physical Structures and Substrates. Fish Fish. 2016, 17, 1-30. [CrossRef]

50. Boissy, A.; Manteuffel, G.; Jensen, M.B.; Moe, R.O.; Spruijt, B.; Keeling, L.J.; Winckler, C.; Forkman, B.; Dimitrov, I.; Langbein, J.; et al. Assessment of Positive Emotions in Animals to Improve Their Welfare. Physiol. Behav. 2007, 92, 375-397. [CrossRef]

51. Kittilsen, S. Functional Aspects of Emotions in Fish. Behav. Processes 2013, 100, 153-159. [CrossRef] [PubMed]

52. O'Connell, L.A.; Hofmann, H.A. The Vertebrate Mesolimbic Reward System and Social Behavior Network: A Comparative Synthesis. J. Comp. Neurol. 2011, 519, 3599-3639. [CrossRef] [PubMed]

53. Chandroo, K.; Duncan, I.J.; Moccia, R. Can Fish Suffer? Perspectives on Sentience, Pain, Fear and Stress. Appl. Anim. Behav. Sci. 2004, 86, 225-250. [CrossRef]

54. Winberg, S.; Nilsson, G.E. Roles of Brain Monoamine Neurotransmitters in Agonistic Behaviour and Stress Reactions, with Particular Reference to Fish. Comp. Biochem. Physiol. Part C Pharmacol. Toxicol. Endocrinol. 1993, 106, 597-614. [CrossRef]

55. Thompson, R.R.; Walton, J.C. Peptide Effects on Social Behavior: Effects of Vasotocin and Isotocin on Social Approach Behavior in Male Goldfish (Carassius Auratus). Behav. Neurosci. 2004, 118, 620-626. [CrossRef]

56. Braithwaite, V. Do Fish Feel Pain? Oxford University Press: New York, NY, USA, 2010.

57. Sneddon, L.U. Pain in Aquatic Animals. J. Exp. Biol. 2015, 218 Pt 7, 967-976. [CrossRef]

58. Sneddon, L.U. The Evidence for Pain in Fish: The Use of Morphine as an Analgesic. Appl. Anim. Behav. Sci. 2003, 83, 153-162. [CrossRef]

59. Rolls, E.T. On the Brain and Emotion. Behav. Brain Sci. 2000, 23, 219-228. [CrossRef]

60. Al-Imari, L.; Gerlai, R. Sight of Conspecifics as Reward in Associative Learning in Zebrafish (Danio Rerio). Behav. Brain Res. 2008, 189, 216-219. [CrossRef] 
61. Soares, M.C.; Oliveira, R.F.; Ros, A.F.H.; Grutter, A.S.; Bshary, R. Tactile Stimulation Lowers Stress in Fish. Nat. Commun. 2011, 2, 534. [CrossRef] [PubMed]

62. Bshary, R.; Würth, M. Cleaner Fish Labroides Dimidiatus Manipulate Client Reef Fish by Providing Tactile Stimulation. Proc. R. Soc. Lond. Ser. B Biol. Sci. 2001, 268, 1495-1501. [CrossRef]

63. Franks, B.; Graham, C.; von Keyserlingk, M.A.G. Is Heightened-Shoaling a Good Candidate for Positive Emotional Behavior in Zebrafish? Animals 2018, 8, 152. [CrossRef] [PubMed]

64. Ghazali, S. Fish Vocalisation: Understanding Its Biological Role from Temporal and Spatial Characteristics. Ph.D. Thesis, Auckland University, Auckland, New Zealand, 2011.

65. Nilsson, J.; Kristiansen, T.S.; Fosseidengen, J.E.; Fernö, A.; van den Bos, R. Learning in Cod (Gadus Morhua): Long Trace Interval Retention. Anim. Cogn. 2008, 11, 215-222. [CrossRef] [PubMed]

66. Bottjer, S.W.; Scobie, S.R.; Wallace, J. Positive behavioral contrast, autoshaping, and omission responding in the goldfish (Carassius auratus). Anim. Learn. Behav. 1977, 5, 336-342. [CrossRef]

67. Burghardt, G.M.; Dinets, V.; Murphy, J.B. Highly repetitive object play in a cichlid fish (Tropheus duboisi). Ethology 2015, 121, 38-44. [CrossRef]

68. Ahloy-Dallaire, J.; Espinosa, J.; Mason, G. Play and Optimal Welfare: Does Play Indicate the Presence of Positive Affective States? Behav. Processes 2018, 156, 3-15. [CrossRef]

69. Oliveira, A.F.S.; Rossi, A.O.; Silva, L.F.R.; Lau, M.C.; Barreto, R.E. Play Behaviour in Nonhuman Animals and the Animal Welfare Issue. J. Ethol. 2010, 28, 1-5. [CrossRef]

70. Spinka, M.; Newberry, R.C.; Bekoff, M. Mammalian play: Training for the unexpected. Q. Rev. Biol. 2001, 76, 141-168. [CrossRef]

71. Bekoff, M. Social Play Behavior. Bioscience 1984, 34, 228-233. [CrossRef]

72. Fagen, R.M. Salmonid Jumping and Playing: Potential Cultural and Welfare Implications. Animals 2017, 7, 42. [CrossRef]

73. Brown, C.; Laland, K. Social Learning and Life Skills Training for Hatchery Reared Fish. J. Fish Biol. 2001, 59, 471-493. [CrossRef]

74. Brown, C.; Laland, K.N. Social Learning in Fishes: A Review. Fish Fish. 2003, 4, 280-288. [CrossRef]

75. McNulty, J.K.; Fincham, F.D. Beyond Positive Psychology? Toward a Contextual View of Psychological Processes and Well-Being. Am. Psychol. 2012, 67, 101-110. [CrossRef] 